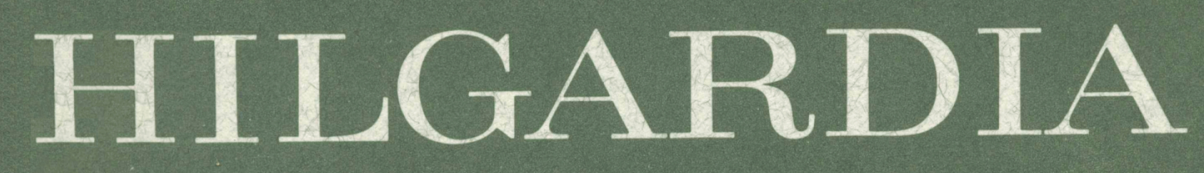

A JOURNAL OF AGRICULTURAL SCIENCE PUBLISHED BY THE CALIFORNIA AGRICULTURAL EXPERIMENT STATION

Volume 39, Number 12 - August, 1968

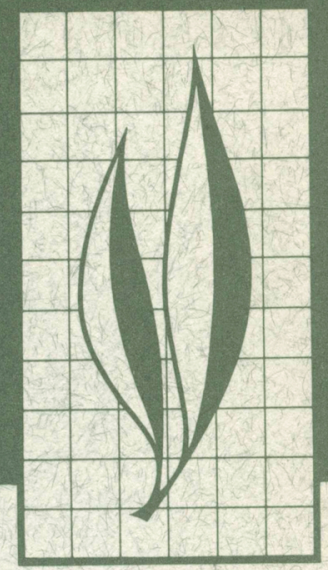

\title{
A Cost-Effectiveness Analysis of Simulated Forest Fire Detection Systems
}

P. H. Kourtz and W. G. O'Regan 


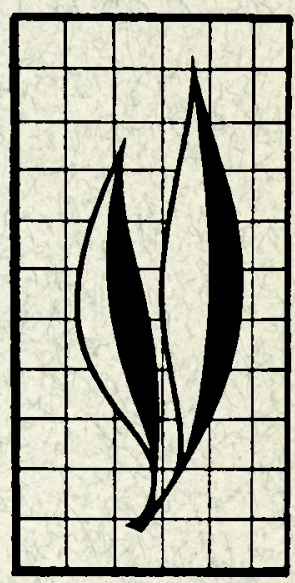

A solution to the problem of finding the most effective lookoutaircraft forest fire detection system for a specific budget is presented. Generated fire and weather data, based on past probability distributions, are used to produce a forest fire detection environment. Within this environment, many feasible all-lookout, all-aircraft, and combined lookout-aircraft detection systems are simulated. Each alternative is constrained by a fixed budget and each is evaluated in terms of a common criterion.

To illustrate the method, hypothetical data, similar to that available to forest protection agencies are used. Five budget levels are examined and the most effective alternatives and corresponding operating rules are identified.

THE AUTHORS:

P. H. Kourtz is a graduate student in Forestry and Research Assistant in the School of Forestry and Conservation, Berkeley, and Research Officer, Forest Fire Research Institute, Canadian Department of Forestry and Rural Development.

W. G. O'Regan is Mathematical Statistician, U.S. Department of Agriculture, Forest Service, Pacific Southwest Forest and Range Experiment Station, and Lecturer in Forestry and Conservation, Berkeley. 


\section{A Cost-Effectiveness Analysis of Simulated Forest Fire Detection Systems ${ }^{1}$}

\section{INTRODUCTION}

FOREST FIRE LOOKOUTS have been relied upon since forest protection agencies first began to protect the forests from wildfire. With the development of light aircraft came the idea of supplementing these lookouts with air patrols in inadequately protected areas. The apparent success of these supplementary air patrols encouraged a few protection agencies to change from a lookout-based detection system to an all-aircraft detection system. The agencies that are still relying on a lookout-based system have an interest in the most effective combination of lookouts and air patrol for their particular lookout arrangement, economic conditions, and fire occurrence frequencies.

In the past, decisions regarding the form of detection systems were made mainly on an intuitive basis. It was impossible to rank objectively the available alternatives in order of efficiency. Experiments were carried out to compare the abilities of lookouts and air patrols to detect fires under various conditions (Harris and Fahnestock, 1954). But these experiments dealt with only part of the total problem. For given operating budgets it was never shown that aircraft-based systems were more effective or less effective in detecting fires than lookout-based systems.
There is a risk involved in relying upon aircraft that must be carefully evaluated. Over a given area, during the time interval between air patrols no detection system exists and fires starting after the last patrol will burn undetected until the next patrol or until detected by other means. In assessing this risk the question arises as to the choice of number, time, and location of air patrols. The answers to this question will depend on the amount of money to be spent on detection or the desired goals that the detection system is attempting to achieve.

Lookouts, on the other hand, detect fires that are within their visual range soon after they are detectable. However, in many sections of the country, visibility is poor on many days, and at the same time, because of limited operating budgets, lookouts are spaced far apart. These two facts frequently result in large gaps in the lookout detection system; in these gaps, fires can burn undetected for long periods of time.

With increasing pressures to reduce losses caused by forest fires, all aspects of fire control including detection systems are being carefully studied. This report describes one possible approach that a fire-detection planner might take to determine the best lookout-aircraft

\footnotetext{
${ }^{1}$ Submitted for publication January 16, 1968.
} 
combination for his specific fire and economic conditions. To illustrate the decision-making process, an example is presented that is based on hypothetical data similar to the data available to most protection agencies. In the example, fire and weather conditions similar to those of the past are developed. Many economically feasible lookout and air patrol combinations are simulated within this environment for each of five budgets. Each detection alternative is evaluated in terms of a common measure of effectiveness. Based on this measure, the most effective detection alternative is found for each budget. However, the measure of effectiveness (average area burned per fire up to the time of detection), used in the example does not consider all aspects of the problem. The final answers can only be obtained after experienced decision makers combine the information provided by this approach with all other relevant information.

\section{DESIGN OF A DETECTION SYSTEM}

The basis of every detection system is a set of rules that govern the operation of the system's physical components. A change in these rules results in a different detection system. This study deals with sets of lookout-aircraft operating rules that result in economically feasible detection systems for specific budgets.

Factors that influence effectiveness of detection systems should be considered when sets of operating rules are devised. Some of the important factors are: number of fires, occurrence time of each fire, fuel condition, humidity, temperature, rate of fire spread, visibility, location of fires, detection budget, number of lookouts operated, locations of lookouts, amount, location, and times of air patrols, visual range of lookouts and aircraft, versatility of lookouts and aircraft, reliability of lookouts and aircraft observers, and altitude of air patrols and topography.

Many of the factors affecting the effectiveness of a detection system can be classified into one of two categories: design factors-items influenced or controlled by man, and environmental factors-items not under man's control. Within these two categories a further classification is possible. The elements having common properties can be grouped into events. For instance, the interaction of fuel conditions, humidity, temperature and rate of fire spread can be summarized by the daily danger index. Thus the daily occurrence of a particular danger index may be considered an event.

The scope and comprehensiveness of the study are defined in the process of listing and grouping the design and environment factors. Some of the more important limitations placed on this study are presented below.

A. It is intended that the approach developed in this study will be used by an existing forest protection agency to assess the worth of new detection alternatives. Thus the approach will be used to evaluate future long-run changes in detection policy and also to evaluate midseason revisions in the current detection plan brought about by a changed economic situation.

B. Because mast forest protection agencies rely upon a network of previously established lookouts, it is assumed that lookouts have already been positioned. This assumption, of course, does not limit the evaluation of new lookout locations. Final results produced by this approach indicate, for each budget, which of the existing or potential lookouts should be operated.

C. The decision to man specific lookouts is made on a long-term basis. 
The number and location of manned lookouts are not changed from day to day. However, air patrol intensities and routes change daily with changing danger index classes according to a predetermined set of rules based on fire occurrence and danger index patterns and budget.

D. The visual range of each lookout is determined by noon visibility and not by topography. Also, the strip width covered by an aircraft is equal to the current day's lookout visibility.

E. The danger index class is used as an indicator of the expected number of fires to occur each day. Lightning-caused fires are not recognized as a separate class of fires.

F. A significant proportion of the total number of fires occurring in the protection unit are detected by the public. This mode of detection is accomplished by tourists, local residents, commercial aircraft and other agencies that use the forest. Given a long enough time period, this mode of detection will detect all detectable fires.

G. Lookouts are operated each day of the fire season and their total cost per day includes lookout depreciation, maintenance costs, and wages. No reduction in this rate is obtained for operating more than one lookout and no penalty is incurred for closing a lookout.

H. Aircraft costs are charged on an hourly basis and the rate includes all aircraft costs plus the wages of a pilot and observer. This hourly rate is independent of the number of hours that an aircraft is used.

I. It is assumed that daily danger index is an adequate predictor of the growth rate of a fire. All fires are assumed to be burning in some undefined average fuel type.

J. The altitude of each air patrol, the skill of the lookout and aircraft observers, and the versatility of the lookouts and aircraft are not considered.

K. Air patrol search patterns are simplified to the point that each pattern can be stated in terms of three variables-width of the strip covered by the air patrol, fire occurrence sector in which the patrol is carried out, and the number of square miles to be covered in each sector.

Decisions were made regarding the interaction of the various events and the order that each was to be considered. The flow diagram showing the interaction of the design and environment events and their relation to the criterion can be seen in figure 1 .

No special optimizing technique was used to find the most effective detection system for each budget. Instead, a large number of the most promising alternatives were examined at each budget level, and their worth evaluated in terms of a common measure of effectiveness. The most effective alternative of those examined was assumed to be the best possible alternative for the particular budget.

\section{THEORY OF THE COST-EFFECTIVENESS APPROACH}

The cost-effectiveness approach considers not only the cost but also, at the same time, the effectiveness of each alternative. In brief, it attempts to discover the alternative that makes the best use of the available resources. In the detection problem the available resource is the money in the detection budget. Effectiveness of resource use must be considered, for if the analyst neglected it, the least expensive alternative would seem to be to do nothing. It is at this point where a conflict arises. It is impossible to maximize effectiveness and 
GENERAL FLOW DIAGRAM FOR THE SIMULATION MODEL

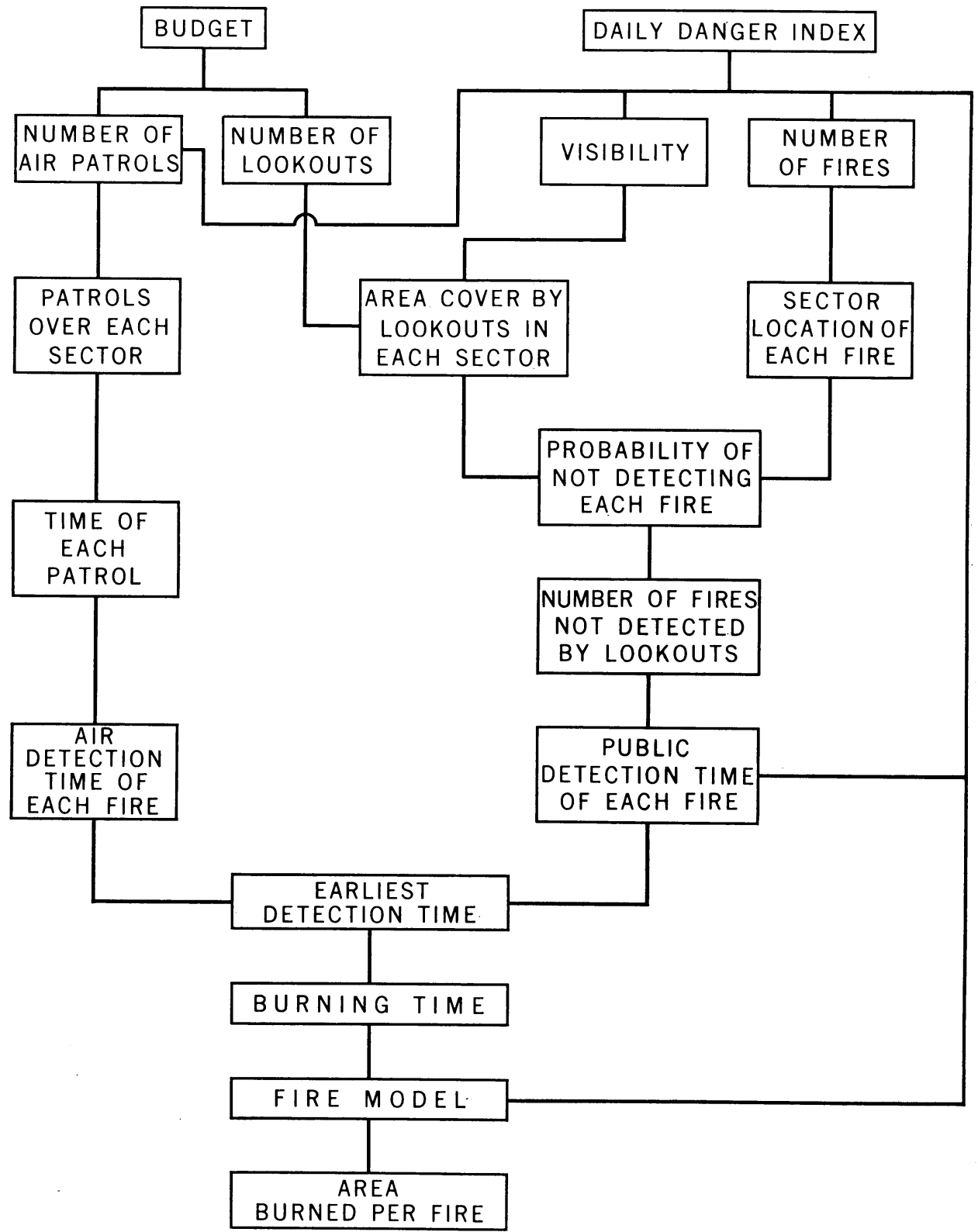

Fig. 1. General flow diagram for the simulation model. 
at the same time minimize cost. The analyst must either fix the amount of money he is willing to spend and attempt to find the most effective alternative for that amount or set the level of effectiveness he wishes to attain and determine the least expensive alternative that will attain this goal.

The alternative that maximizes effectiveness at a given budget level is the same alternative that minimizes the cost of attaining that same level of effectiveness. For example, suppose for a fixed detection budget of 40,000 dollars, analysis showed that an all-aireraft system attained the lowest possible area burned per fire up to the time of detection-this area being five acres. This same problem could have been approached from the other direction. That is, to determine the least expensive alternative that can attain an area burned per fire of five acres. Had this been done, the analyst would have found that the same all-aircraft system achieved this level of effectiveness for 40,000 dollars-the least expensive of all the alternatives capable of achieving this effectiveness level. Thus these two seemingly different approaches arrive at the same detection alternative.

In our system of government the total amount of money available to be spent by government forestry organizations is determined by the political process. Once the total amount to be spent is set, administrators of the forestry organizations allocate the money for various forestry uses, one of which is forest fire detection. Once the detection budget is set, the administrators of the detection system allocate the money in a manner that they feel will be most effective. For this reason this analysis considered the budget as being fixed and attempted to find the alternative that made the best use of the available money.

\section{Criterion problem}

Up to this point the terms "best use" of available resources and "effectiveness" have been used without a discussion of how they might be measured. If we were dealing with private enterprise, one measure of effectiveness might be the profits received from the various alternatives. Forest fire detection, however, shows no direct monetary revenues and therefore monetary values cannot be used as a measure of detection effectiveness. Some other criterion had to be found.

To measure the effectiveness of a detection system, ideally the analyst should choose the alternative that comes closest to achieving his ultimate goal. Perhaps this goal might be to achieve the maximum value or satisfaction from the forest. Obviously it is impossible at this time to relate the effectiveness of various alternatives to such a goal. Thus, in evaluating detection alternatives, one must be satisfied with a "proximate" criterion which is only distantly related to the true goal but which still reflects what is happening to it (Hitch and McKean, 1960).

On accepting a proximate criterion the analyst accepts the fact that his solution does not consider all interrelated factors that influence the attainment of his ultimate goal. He must limit the number of factors he considers to only those that are readily available and easily handled. This study dealt with a proximate criterion that reflected the cost of fire suppression and the amount of damage caused by fire. Factors such as the influence of fire on the aesthetic and recreational value of the forest were neglected.

The conclusions drawn from the study would be incorrect if the wrong criterion were selected. In fact, an entirely different problem would be solved if the 
criterion were wrong. For this reason a great deal of thought was given to the selection of an appropriate criterion. Some of the criteria considered were:

Detection cost per protected acre or per detected fire. Cost cannot be used because the goal is to maximize effectiveness by appropriate choice of alternatives. The use of this criterion would eliminate the conflict between cast and effectiveness: the most effective alternative would be the least expensive alternative, which would be to operate no detection system.

The amount of damage caused by fire up to the time of detection. This criterion obviously requires an assessment of direct and indirect damages caused by fire. These figures are difficult and in most situations impossible to attain at this time. This criterion also neglects the suppression effort and damage caused after the fire is detected.

The total cost of detection, suppression and damage. This criterion approaches closest to the true goal at this level of optimization, but must be ruled out because the true damage and suppression costs cannot be measured at this time.
The expected burning time of a fire up to the time of detection. The final size of a fire and the difficulty of suppression are related to the elapsed time from ignition to detection and to the rate of spread of the fire. Thus elapsed time alone is not the only important factor affecting the damage and suppression costs caused by a fire. Total area burned before detection on an annual basis. This criterion contains one major fault: the number of fires and thus the total area burned up to the time of detection varies widely from year to year.

Average area burned per fire up to the time of detection. This criterion does not require the measurement of the cost of suppression or the amount of damage caused by fires, and thus avoids the complexities of these factors. However, the size of the fire at detection greatly influences the job load of the suppression organization and the final area burned by the fire. Therefore, this criterion considered important "spillover" effects on the other activities related to detection (Hitch and McKean, 1960). This criterion appeared to fit the situation best and was chosen for this study.

\section{SIMULATION}

A large problem presented itself when the time came to collect the data required to examine the various detection alternatives. Experiments testing large numbers of detection alternatives have never been carried out; thus, there were no data available. Experiments certainly could be planned and carried out in the future but many years of observations would be required to obtain reliable results. This left only one other approach - the construction of a simulation model capable of abstractly representing a large number of lookoutaircraft alternatives and capable of evaluating the relevant factors influencing the effectiveness of each alternative. Using this model, the most effective al- ternatives among those studied could be identified.

The manipulation of rules governing the interaction of design variables within an environment is known as simulation. In this case, each rule that specified the combination of design variables made up a detection alternative. The design variables used were: number of lookouts, number of flights over the areas not protected by lookouts in each fire occurrence sector on each danger class day, and time of each air patrol. The environmental variables were: daily danger index, daily visibility, number of fires occurring in each fire occurrence sector, and time of occurrence of each fire. 


\section{MAP OF HYPOTHETICAL FOREST PROTECTION UNIT}

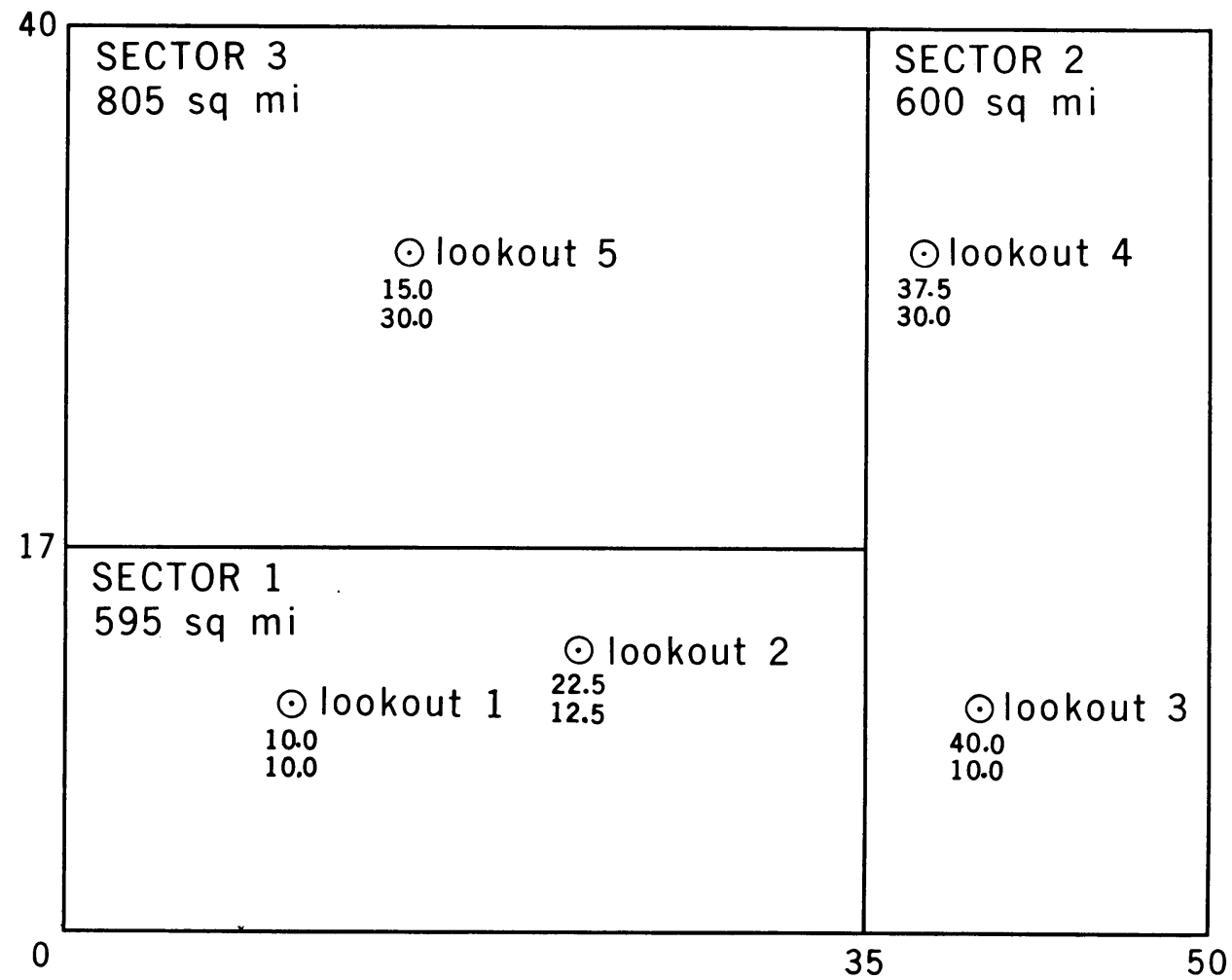

\section{MILES}

Fig. 2. Map of hypothetical forest protection unit.

\section{Description of the protection unit}

To demonstrate the cost-effectiveness and simulation approach in solving for the best detection system, an example based on hypothetical data is presented. For this example a forest protection unit 40 miles wide and 50 miles long was devised. It was assumed that five lookouts had previously been established in the area. The location of these lookouts can be seen in figure 2 .

In an area as large as 2,000 square miles, subdivisions based on frequency of fire occurrence can usually be made This fact has been used for many years by fire detection planners to locate lookouts and air patrol routes. For this reason the hypothetical protection unit was divided into three fire occurrence sectors. Given a fire, the probabilities of it occurring in sectors one, two, and three were set at $0.60,0.30$ and 0.10 respectively. The areas of sectors one, two, and three were 595, 600 and 805 square miles, respectively. The dimensions and location of the sectors are illustrated in figure 2. The data required to construct fire occurrence sectors are usually readily available from fire report records. 


\section{Daily danger index generator}

How can a long-range plan for a future detection system be designed when the number of fires that will occur tomorrow cannot even be accurately predicted? Obviously, any plan that is drawn up can only be based on what the designer expects will happen in the future. In this study, the best that could be done was to assume that the future pattern of events would be about like that of the recent past. It was not assumed that the pattern was exactly the same, but that the probability distributions of the relevant events were constant. Thus, generators were required to produce event patterns that might occur in the future and that would serve as a basis for the evaluation of detection alternatives.

The generation of events was carried out by a computer that randomly selected numbers from a uniform probability distribution and matched these numbers to the appropriate classes of the cumulative probability distribution of the event being generated. Although the probability distributions used in this study were not based on actual data, it was intended that they would be representative of data from a northeastern forest protection unit.

The criterion that was chosen required a measure of the area burned up to the time of detection for each fire. The area of a fire at a specified time interval after ignition depends on the rate of spread of the fire and the length of the time interval. Parks (1964) developed a general fire-spread model that predicted area burned for a given elapsed time interval and rate of fire spread. His model was used to determine the effectiveness of each alternative. The danger index, used by forest protection agencies, is a relative measure of the expected rate of spread of a fire. Therefore, to obtain effectiveness measurements using Parks' fire model it was necessary to know:
The daily danger index and the relation of the danger index to the rate of spread

The time at which a fire starts and the time at which it is detected.

Daily danger index was the key environmental event in the model. Assumed to be related to it were daily visibility, number of fires occurring each day, rate of spread of a fire, time required for the public to detect each fire, and time and number of air patrols carried out each day. To simplify the generation procedure only three danger index classes were considered-low, moderate, and high. The probability distribution for the current day's danger index class was considered to be conditional on the previous day's danger index class. For example, it was much more likely that a low- or moderate-danger day, rather than a high-danger day, would follow a low-danger day.

UPPER LIMITS OF THE CUMULATIVE DISTRIBUTIONS

\begin{tabular}{l|l|l|l}
\hline \hline Danger & Spring & Summer & Fall \\
\hline
\end{tabular}

A) Given a low-danger day the previous day:

\begin{tabular}{l|l|l|l}
\hline Low...................... & 0.70 & 0.50 & 0.70 \\
Moderate.............. & 0.95 & 0.95 & 0.95 \\
High.................. & 1.00 & 1.00 & 1.00 \\
\hline
\end{tabular}

B) Given a moderate-danger day the previous day:

\begin{tabular}{l|l|l|l}
\hline Low $\ldots \ldots \ldots \ldots \ldots \ldots \ldots \ldots$ & 0.60 & 0.35 & 0.60 \\
Moderate................ & 0.90 & 0.85 & 0.90 \\
High.................. & 1.00 & 1.00 & 1.00 \\
\hline
\end{tabular}

C) Given a high-danger day the previous day:

\begin{tabular}{l|l|l|l}
\hline Low...................... & 0.35 & 0.25 & 0.35 \\
Moderate............... & 0.85 & 0.65 & 0.85 \\
High................. & 1.00 & 1.00 & 1.00 \\
\hline
\end{tabular}

Unfortunately the danger index probability distributions change within each fire season because of seasonal changes. To overcome this problem three sets of distributions representing the spring, summer, and fall seasons were intro- 
duced. Shown here are the hypothetical conditional cumulative probability distribution that was used in the generation of daily danger index classes. Conditional distributions similar to those shown above can be assembled from several seasons of daily danger index data.

To determine each day's danger index, a number between zero and one was randomly selected from a uniform distribution. This number was compared to the appropriate danger index distribution to determine the cumulative distribution class in which the number fell. The danger index represented by that class was the current day's danger index. For example, given that the day was in the summer period, the previous day's index was moderate and the random number was 0.72 , the danger index for the current day would be moderate. If the random number had been 0.86 or larger the danger index would have been high.

A typical pattern of daily danger indexes produced by the generator is given below. The integer 1 indicates a low danger day, 2 a moderate day and 5 a high danger day.

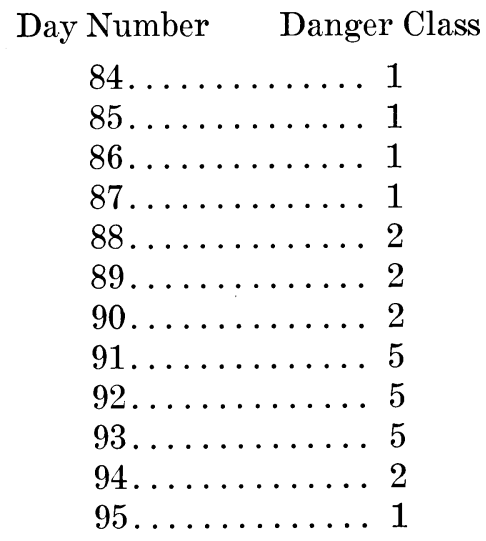

The maximum length of the spring, summer, and fall periods were 30,153 , and 17 days, respectively. A set of simple rules was incorporated into the danger index generators to start and end the fire season. The rules chosen to begin and end the fire season were:

If two moderate or one moderate and one high or two high days occurred in a row, the season started. If this did not occur during the spring period, the summer period started on day 31 .

If four consecutive low danger days occurred in the fall period the fire season stopped. If this series did not occur, the fire season was ended 200 days after the beginning of the spring period.

This method of beginning and ending the fire seasons, caused the season lengths to vary considerably as they do in the real-life situation. Ten years of daily danger index data were generated. The performance of the danger index generator with regard to the beginning, ending, and length of each fire season are shown here.

\begin{tabular}{|c|c|c|c|}
\hline Fire season & $\begin{array}{l}\text { In Spring } \\
\text { period }\end{array}$ & $\underset{\text { period }}{\text { In Fall }}$ & $\begin{array}{l}\text { Season } \\
\text { length }\end{array}$ \\
\hline & days & days & days \\
\hline $1 \ldots \ldots \ldots \ldots \ldots \ldots$ & 23 & 1 & 177 \\
\hline $2 \ldots \ldots \ldots \ldots \ldots \ldots$ & 14 & 3 & 170 \\
\hline $3 \ldots \ldots \ldots \ldots \ldots$ & 12 & 3 & 168 \\
\hline $4 \ldots \ldots \ldots \ldots \ldots$ & 27 & 17 & 197 \\
\hline $5 \ldots \ldots \ldots \ldots$ & 24 & 5 & 182 \\
\hline $6 \ldots \ldots \ldots$ & 26 & 4 & 183 \\
\hline $7 \ldots \ldots \ldots \ldots$ & 2 & 17 & 172 \\
\hline $8 \ldots$ & 23 & 3 & 179 \\
\hline $9 \ldots \ldots \ldots \ldots \ldots$ & 16 & 4 & 173 \\
\hline $10 \ldots \ldots \ldots \ldots \ldots$ & 26 & 15 & 194 \\
\hline
\end{tabular}

\section{Daily visibility generator}

The maximum visibility possible for any day was set at 15 miles. It is doubtful if smoke from a small fire can be seen beyond this limit even on the clearest of days. Four visibility classes were used in the generator. These were 6,9 , 12 , and 15 miles. The daily visibility was considered to be partially dependent on the current day's danger index. For example, if the danger index were low, visibility was likely to be poor. To determine each day's visibility, a ran- 
dom number between zero and one was compared to the appropriate visibility distribution to determine in which cumulative distribution class the number fell. The visibility represented by that class was the current day's visibility. The hypothetical conditional cumulative probability distributions are shown here.

\begin{tabular}{c|c|c|c}
\hline \hline \multirow{2}{*}{$\begin{array}{c}\text { Current day } \\
\text { visibility }\end{array}$} & \multicolumn{2}{|c}{ Current day's danger } \\
\cline { 2 - 3 } & Low & Moderate & High \\
\hline $6 \ldots \ldots \ldots \ldots \ldots \ldots \ldots$ & 0.30 & 0.10 & 0.05 \\
$9 \ldots \ldots \ldots \ldots \ldots \ldots \ldots$ & 0.60 & 0.45 & 0.20 \\
$12 \ldots \ldots \ldots \ldots \ldots \ldots \ldots$ & 0.85 & 0.80 & 0.70 \\
$15 \ldots \ldots \ldots \ldots \ldots \ldots \ldots$ & 1.00 & 1.00 & 1.00 \\
\hline
\end{tabular}

\section{Fire generator}

The number of fires occurring each day was assumed to be described by a Poisson distribution, conditional upon the danger index. The average number of fires per danger index class day was used as the Poisson parameter:

\begin{tabular}{|c|c|}
\hline Danger class & $\begin{array}{l}\text { Average number } \\
\text { of fires per day }\end{array}$ \\
\hline High...... & 1.60 \\
\hline 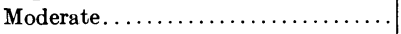 & 0.50 \\
\hline 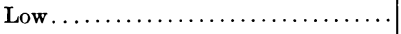 & 0.05 \\
\hline
\end{tabular}

The cumulative probabilities for the occurrences of fires were then calculated:

\begin{tabular}{|c|c|c|c|}
\hline \multirow{2}{*}{ Number of fires } & \multicolumn{3}{|c|}{ Current day's danger } \\
\hline & Low & Moderate & High \\
\hline $0 \ldots \ldots \ldots \ldots \ldots \ldots$ & 0.95 & 0.61 & 0.20 \\
\hline $1 \ldots \ldots \ldots$ & 0.99 & 0.91 & 0.52 \\
\hline $2 \ldots \ldots \ldots$ & 1.00 & 0.98 & 0.78 \\
\hline $3 \ldots \ldots$ & $\ldots$ & 0.99 & 0.92 \\
\hline $4 \ldots \ldots \ldots$ & $\cdots$ & 1.00 & 0.97 \\
\hline $5 \ldots \ldots \ldots \ldots \ldots \ldots$ & $\ldots$ & $\ldots$ & 0.99 \\
\hline $6 \ldots \ldots \ldots \ldots \ldots \ldots$ & $\ldots$ & $\ldots$ & 1.00 \\
\hline
\end{tabular}

By knowing the danger index and a randomly selected number from a uni- form distribution, the number of fires occurring each day was determined. For example, if the random number drawn in the fire generator were 0.72 and the current day's danger index were low, there would be no fires for that day. If the danger index were high, there would be two fires that day.

\section{Fire occurrence time generator}

To calculate the area burned by each fire up to the time of detection it was necessary to know at what time during the day each fire started. This information is usually readily available from fire report forms and could be compiled, given time, to obtain a fire-start distribution. For this study, the general form of the distribution used to generate the occurrence time of each fire was taken from Barrows (1951). For each fire, a random number between zero and one was matched to the cumulative probability distribution. Depending on which class the number fell, the time of occurrence was established. It was assumed that fires could start during a ten-hour period each day. The occurrence time distribution data is shown here.

\begin{tabular}{|c|c|}
\hline Hour of occurrence & $\begin{array}{c}\text { Cumulative } \\
\text { Distribution } \\
\text { classes }\end{array}$ \\
\hline $1 \ldots \ldots \ldots \ldots \ldots \ldots \ldots \ldots \ldots \ldots \ldots \ldots$ & 0.07 \\
\hline $2 \ldots \ldots \ldots \ldots \ldots \ldots \ldots \ldots$ & 0.15 \\
\hline 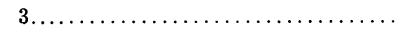 & 0.25 \\
\hline $4 \ldots \ldots \ldots \ldots \ldots \ldots \ldots \ldots \ldots \ldots \ldots$ & 0.37 \\
\hline $5 \ldots \ldots \ldots \ldots \ldots \ldots \ldots \ldots \ldots \ldots \ldots \ldots$ & 0.52 \\
\hline 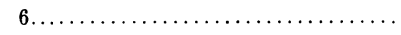 & 0.68 \\
\hline $7 \ldots \ldots \ldots \ldots \ldots \ldots \ldots \ldots \ldots \ldots \ldots \ldots \ldots \ldots \ldots$ & 0.81 \\
\hline $8 \ldots \ldots \ldots \ldots \ldots \ldots \ldots \ldots \ldots \ldots \ldots$ & 0.91 \\
\hline $9 \ldots \ldots \ldots \ldots \ldots \ldots \ldots \ldots \ldots \ldots$ & 0.96 \\
\hline 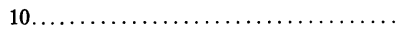 & 1.00 \\
\hline
\end{tabular}

\section{Fire location generator}

The fire location generator located each fire into one of the three fire occurrence sectors. The specific locations of each fire within a sector was not required since it was assumed that the distribution of fires within a sector was 
uniform. The generator fitted as many random numbers, as fires occurring that day, into the proper cumulative distribution classes:

\begin{tabular}{c|c}
\hline \hline Sector location of the fire & $\begin{array}{c}\text { Upper limits of the } \\
\text { cumulative distribu- } \\
\text { tion classes }\end{array}$ \\
\hline $1 \ldots \ldots \ldots \ldots \ldots \ldots \ldots \ldots \ldots \ldots \ldots \ldots \ldots$ & 0.60 \\
$2 \ldots \ldots \ldots \ldots \ldots \ldots \ldots \ldots \ldots \ldots \ldots \ldots$ & 0.90 \\
$3 \ldots \ldots \ldots \ldots \ldots \ldots \ldots \ldots \ldots \ldots \ldots \ldots$ & 1.00 \\
\hline
\end{tabular}

Using this approach it was possible to state the number of fires occurring in each sector during each day of the fire season.

\section{Public detection generator}

As mentioned, if no air or lookout system is operating, each fire will eventually be detected by the public. Even when a detection system is operating, a fire will frequently be first detected by the public.

\section{UPPER LIMITS OF THE CUMULATIVE DISTRIBUTION CLASSES}

\begin{tabular}{|c|c|c|c|}
\hline \multirow{2}{*}{$\underset{\text { time }}{\text { Burning }}$} & \multicolumn{3}{|c|}{ Current day's danger } \\
\hline & Low & Moderate & High \\
\hline hours & & & \\
\hline $1 \ldots \ldots \ldots \ldots \ldots$ & $\ldots \ldots$ & 0.047 & 0.135 \\
\hline $2 \ldots \ldots \ldots \ldots \ldots$ & 0.003 & 0.125 & 0.436 \\
\hline $3 \ldots \ldots \ldots$ & 0.010 & 0.265 & 0.677 \\
\hline $4 \ldots \ldots \ldots$ & 0.029 & 0.440 & 0.857 \\
\hline $5 \ldots \ldots \ldots$ & 0.067 & 0.616 & 0.947 \\
\hline $6 \ldots \ldots \ldots \ldots \ldots$ & 0.130 & 0.762 & 0.983 \\
\hline $7 \ldots \ldots \ldots \ldots \ldots$ & 0.220 & 0.867 & 0.995 \\
\hline $8 \ldots \ldots \ldots \ldots \ldots$ & 0.333 & 0.932 & 1.000 \\
\hline $9 \ldots \ldots \ldots$ & 0.458 & 0.968 & \\
\hline $10 \ldots \ldots \ldots \ldots \ldots$ & 0.883 & 0.986 & \\
\hline $11 \ldots \ldots \ldots \ldots \ldots$ & 0.697 & 0.995 & \\
\hline $12 \ldots \ldots \ldots \ldots \ldots$ & 0.792 & 0.998 & \\
\hline $13 \ldots \ldots \ldots \ldots \ldots$ & 0.864 & 1.000 & \\
\hline $14 \ldots \ldots \ldots \ldots \ldots$ & 0.917 & & \\
\hline $15 \ldots \ldots \ldots \ldots \ldots$ & 0.951 & & \\
\hline $16 \ldots \ldots \ldots$ & 0.973 & & \\
\hline $17 \ldots \ldots$ & 0.986 & & \\
\hline $18 \ldots \ldots \ldots \ldots \ldots$ & 0.993 & & \\
\hline $19 \ldots \ldots \ldots \ldots \ldots$ & 1.000 & & \\
\hline
\end{tabular}

Each fire was given a number that represented the elapsed time in hours between the time when the fire was first detectable until it would be detected by the public. It was assumed that the elapsed time distribution was Poisson and conditional on the daily danger index. The actual distribution for a specific area could be approximated from the fires detected by the public. The cumulative distributions used in the generator are given in the table left below:

To generate a burning time for each fire a random number was fitted into the appropriate distribution class as was done in the previous generators.

Computer programs were written to generate the data and to merge the results onto one set of data cards.

\section{Fire spread model}

The fire spread model developed by Parks (1964) is

$$
\mathrm{dA} / \mathrm{dT}=\mathrm{G}+\mathrm{HT}
$$

Where- $A$ is the area burned in acres after an elapsed time of $\mathrm{T}$ hours.

$\mathrm{G}$ is the linear growth rate in acres per hour.

$\mathrm{H}$ is acceleration expressed in hours and acres.

Integrating this with respect to time, we obtain

$$
\mathrm{A}=\mathrm{G}, \mathrm{T}+\left(\mathrm{HT}^{2} / 2\right)
$$

Time, for this model, was measured from the time the fire was first detectable to the time the fire was actually detected. The detectable time of each fire was assumed to be the time generated by the fire occurrence time generator. The area of a fire when it was first detectable was assumed to be zero. This assumption is probably valid on moderate-and high-danger days.

The danger index was used as an indicator of the rate of spread of a fire. The relationship of danger index to the

\begin{tabular}{|c|c|c|}
\hline Danger class & G & $\mathbf{H}$ \\
\hline Low........... & 0.10 & 0.05 \\
\hline 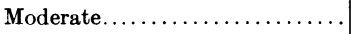 & 0.50 & 0.10 \\
\hline High...................... & 2.00 & 0.50 \\
\hline
\end{tabular}
fire model parameters is shown here: 


\section{THE ALL-LOOKOUT SECTION OF THE MODEL}

A mathematical model in the form of a large computer program was developed to evaluate the all-lookout, all-aircraft, and combined detection alternatives. The model calculated the average area burned per fire for each combination of design variables tested. The average was based on the ten fire seasons of environmental data that previously had been produced by the event generation process.

The cost-effectiveness approach required that the best use of available resources be made at each budget level. Related to the all-lookout detection system, this meant that if enough money were available to operate $\mathrm{N}$ lookouts, the $\mathrm{N}$ lookouts that were chosen out of all those possible should make up the most effective $\mathrm{N}$ lookout combination. Thus for each budget level, or different number of lookouts operated, the combination that resulted in the smallest average area burned per fire was found. This was done by examining the average area burned per fire resulting from every possible combination of lookouts at each budget level.

The two all-lookout design variables were the number and locations of the lookouts that were to be operated. The environmental variables were daily danger index, daily visibility, daily number and occurrence time of fires in each sector, and corresponding public detection time of fires not detected by lookouts. Each combination of $\mathrm{N}$ lookouts was tested with the same ten years of environmental data and therefore each detection alternative was examined under the same conditions. This procedure is similar to operating many separate detection systems concurrently under the same conditions.

\section{Area calculation program}

It was assumed that the occurrence of a fire was equally likely anywhere within an occurrence sector. This as- sumption meant that the ratio of the area not covered by lookouts in an occurrence sector to the total area of the sector represented the probability of not detecting a given fire in that sector. These probabilities increased as the visibility decreased. To obtain these probabilities, it was necessary to find the area not covered by all possible combinations of lookouts in each occurrence sector for each of the four visibility levels.

Two satisfactory methods were available to find these areas-the dot grid method or the planimeter method. To save time, the dot grid method was used. Visibility was assumed to be the only limiting factor affecting the visual range of the lookouts, permitting use of the computer to find the required areas. Area-seen maps should be used in studies undertaken in an existing protection unit.

The map of the hypothetical protection unit was laid out on a X-Y coordinate system. The sector boundaries and lookout coordinates were given to the computer along with the instructions to count every dot in a dot grid that fell outside the visual range of each lookout. This was done for all possible lookout combinations and visibilities. The computer kept account of the number of points counted in each occurrence sector and also gave the ratio of points counted to the total number of points in each sector. The spacing between points was equivalent to one mile and therefore each counted point represented one square mile. This method of area calculation was very fast and avoided the problem of overlapping lookout coverage.

A sensitivity analysis on the accuracy of the dot counting procedure was carried out. Five lookouts were operated during nine-mile visibility conditions. The spacing between dots was varied from 0.25 miles to 1.75 miles by incre- 
ments of 0.50 miles. The results are presented here:

\begin{tabular}{c|c|c|c}
\hline \hline Dot spacing & Sector 1 & Sector 2 & Sector 3 \\
\cline { 2 - 3 } miles & \multicolumn{2}{|c|}{ percentage of total area not covered } \\
\cline { 2 - 4 } & & 37 & 51 \\
$0.25 \ldots \ldots \ldots \ldots \ldots \ldots \ldots \ldots \ldots \ldots \ldots \ldots$ & 25 & 35 & 51 \\
$1.25 \ldots \ldots \ldots \ldots \ldots \ldots \ldots$ & 21 & 41 & 51 \\
$1.75 \ldots \ldots \ldots \ldots \ldots \ldots$ & 19 & 34 & 45 \\
\hline
\end{tabular}

As the interval between dots decreased, the accuracy of the method increased. But as the distance between the dots decreased the time that the computer required to execute the program significantly increased. For this reason a dot spacing of one mile was selected to estimate the required areas.

\section{Burning fire generator}

It was assumed that lookouts detect all fires within their visual range as soon as the fires are detectable. This meant that to assess the effectiveness of an alllookout system only the fires that started beyond the visual range of the lookouts needed to be considered.

Once the probability of not detecting a fire in a given sector on a given visibility day for a certain lookout combination was known, the expected number of fires occurring outside the range of the lookouts was determined. This was accomplished by selecting a random number for each fire occurring in a sector and comparing it to the appropriate probability of not detecting a fire. If the random number was below this value, the fire was not detected by lookouts.

\section{Calculation of area burned}

The fires not detected by lookouts were detected by the public. The burn- ing fire generator determined which fires to consider and the environmental data provided the necessary information to use the fire model. Available for each fire were:

The danger index for the day the fire started and for subsequent days if the fire burned undetected for more than one day;

The time at which the fire was first detectable;

The time at which the fire was detected by the public.

The area that each fire burned up to the time of detection was calculated. Figure 3 shows the relationships of the various elements considered in the alllookout section of the model.

The burning period each day was assumed to be ten hours. If a fire was not detected during the first ten-hour day, it continued to burn the second day at a rate dictated by the second day's danger index. It was assumed that a lookout cost 15 dollars a day to operate and that during the ten seasons each lookout was operated 1,800 days. Thus the cost of one lookout for the ten fire seasons was 27,000 dollars. The most effective alternatives for the various budget levels are shown below.

\begin{tabular}{c|c|l|c}
\hline \hline 10-year budget & $\begin{array}{c}\text { Number } \\
\text { of } \\
\text { lookouts }\end{array}$ & $\begin{array}{c}\text { Best } \\
\text { lookout } \\
\text { combination* }\end{array}$ & $\begin{array}{c}\text { Lowest area } \\
\text { burned } \\
\text { per fire }\end{array}$ \\
\hline dollars & & & acres \\
$00 \ldots \ldots \ldots \ldots$ & 0 & - & 5.57 \\
$27,000 \ldots \ldots \ldots \ldots$ & 1 & 1 & 3.78 \\
$54,000 \ldots \ldots \ldots \ldots$ & 2 & 1,3 & 2.52 \\
$81,000 \ldots \ldots \ldots \ldots$ & 3 & $1,2,3$ & 1.69 \\
$108,000 \ldots \ldots \ldots \ldots$ & 4 & $1,2,3,4$ & 0.99 \\
$135,000 \ldots \ldots \ldots \ldots$ & 5 & $1,2,3,4,5$ & 0.92 \\
\hline
\end{tabular}

* The locations of lookouts are given in figure 2.

Figure 4 illustrates the all-lookout costeffectiveness curve.

\section{THE ALL-AIRCRAFT SECTION OF THE MODEL}

\section{Design of an air patrol}

In designing an air patrol for a specific area on a given day, the values set for the relevant design variables are dic- tated by the predicted values of certain environmental variables. Daily visibility determines the aircraft's altitude and the visual range of the observer. 


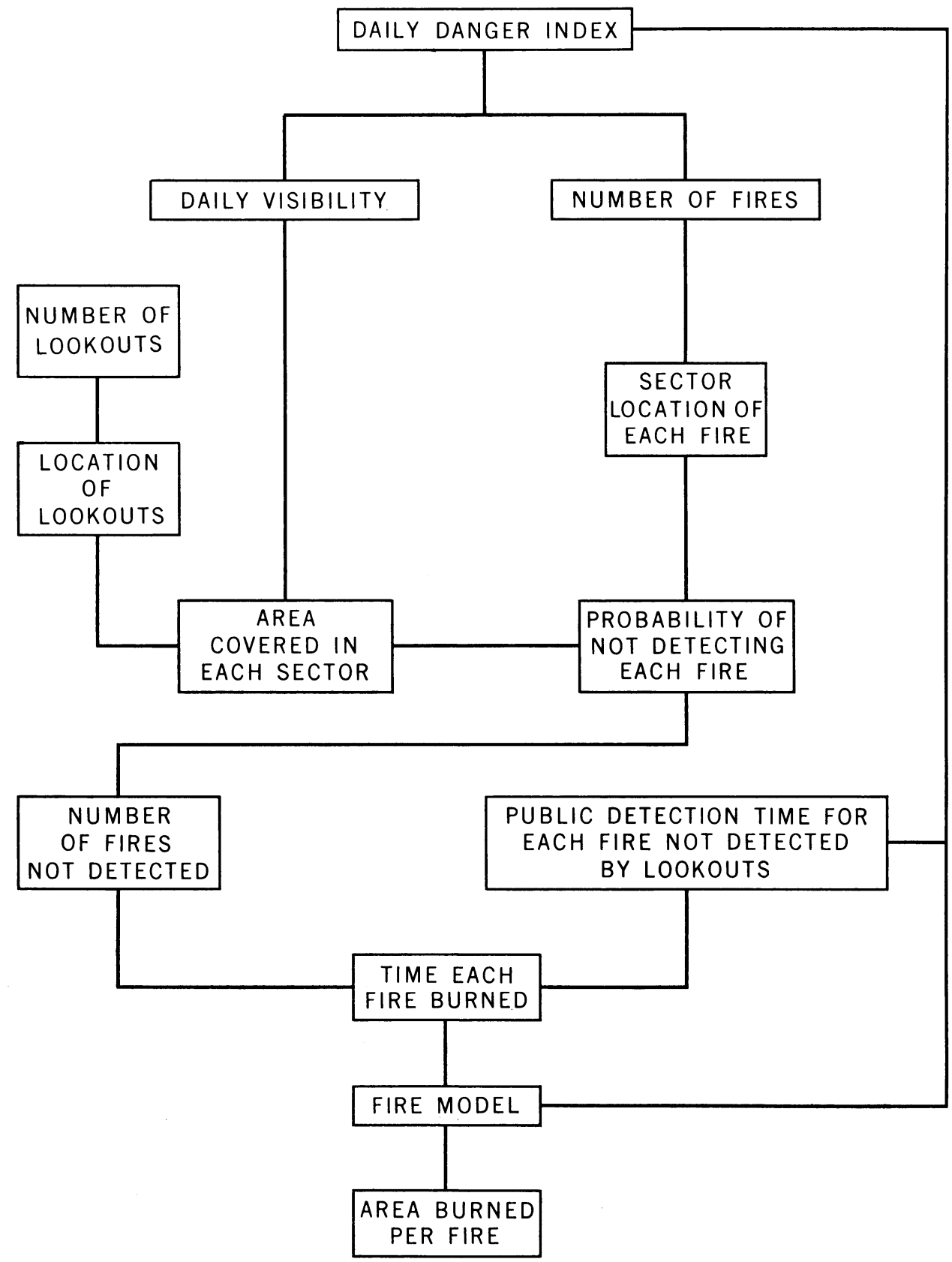

Fig. 3. Flow diagram for the all-lookout section of the model. 


\section{COST EFFECTIVENESS CURVE OF THE ALL-LOOKOUT DETECTION SYSTEM}

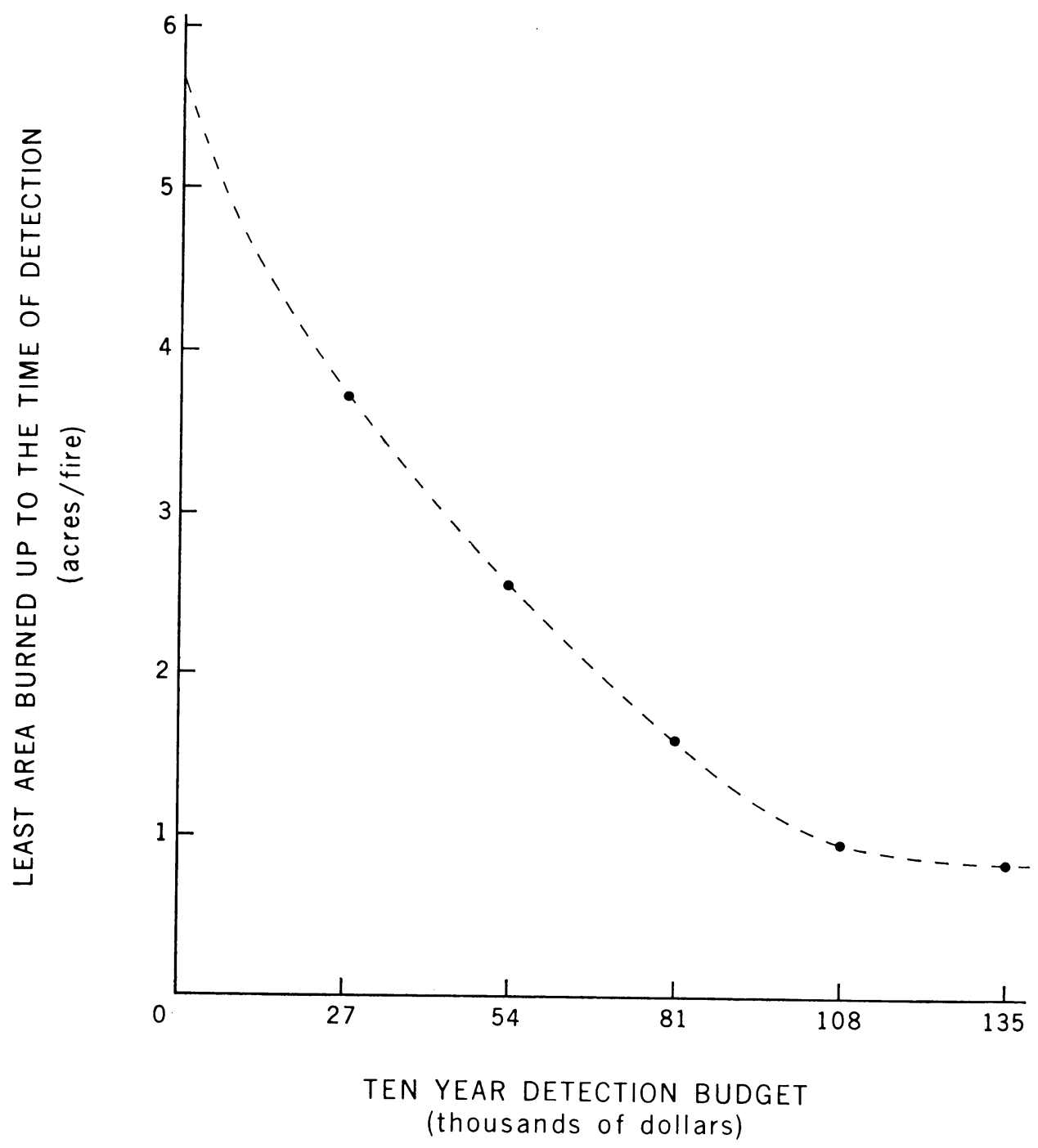

Fig. 4. Cost-effectiveness curve of the all-lookout detection system. 
Visibility range of an aircraft is usually considered to be no better than that of a lookout. As the aircraft increases in altitude, the observer has more haze to look through. Therefore on low-visibility days, the air patrol covers a narrow strip from a low altitude. The pilot of the aircraft usually can find the best altitude at which to fly for each visibility condition. For this reason altitude was not considered as a design variable in the model. In theory, the strip width covered by an air patrol should be approximately equal to the diameter of the circle covered by a lookout or, in other words, twice the lookout visibility. However, air patrol patterns are usually in a zig-zag form and to insure proper coverage of every point, the strip width used in the model was reduced to onehalf that of the theoretical maximum.

Air patrol patterns should be arranged so that duplication of coverage is kept to a minimum while at the same time covering the required areas. To accomplish this, a different flight pattern must be used for each visibility class day. Actual flight patterns should have been laid out and used to obtain the length and location of each flight. However, to save time it was assumed that there was no duplication of coverage by an air patrol. The time required for a complete patrol over an area was calculated by dividing the total area to be covered by the product of the lookout visibility and the speed of the aircraft.

The likelihood of one or more fires occurring, and their probable rate of spread dictate the location and the number of patrols to be carried out each day. The risk of fires and their rate of spread is predicted by the daily danger index. The most likely areas for fires to occur are predicted by fire occurrence maps. In this study, rules regarding the sector locations of patrols and the areas covered by each patrol were devised for each danger class day. A specific set of rules made up an alternative. Rules were changed many times in order to approach the most effective alternative.

The time of each air patrol is governed by the expected occurrence times of fires. Each air patrol should be scheduled so that the smallest average area burned per fire up to the time of detection will be achieved. In this study the time of each air patrol was a design variable. Many different times for the air patrols were examined.

The time required for the aircraft to reach each patrol sector was not considered in this study. This factor could be considered simply by measuring the total length of each flight pattern. The speed and hourly cost of an aircraft were considered. It was assumed that a single engined, pontoon equipped aircraft similar to a piper super-cub was used. The speed of the aircraft was assumed to be 90 miles an hour and its cost (including a pilot, observer, depreciation, and maintenance) was 40 dollars an hour. These values could be changed depending on the specific type of aircraft used.

How many patrols should there be each danger class day? In what fire occurrence sectors should the patrols be carried out? The number and location of air patrols each danger day had to be selected in a way that would spend only the money in the detection budget. The cost of an air detection system for one fire season not only depended on the combination of design variables but also upon the number of days in each danger and visibility class. The unpredictable nature of these environmental factors made it impossible to satisfy exactly an annual budget constraint. The best solution possible was found by examining those combinations of design variables that resulted in an expenditure equal to a ten-year budget.

\section{Allocation of air patrols}

If a specific amount of money, or its equivalent number of aircraft hours, were set aside to be spent on each danger class day, the planned patrol 
flights could, depending on the current day's visibility, result in either duplication or insufficient coverage of a specific area. On a low-visibility day the aircraft time required to cover a specific area is considerably greater than the time required to cover the same area on a high-visibility day. This study allocated the money in the detection budget on a danger class-area basis in order to maintain a consistent detection policy. This meant that a specific number of square miles was patrolled each danger class day regardless of the current day's visibility. The allocation based on area avoided the necessity to consider daily visibilities and daily cost of air patrols in the model. The formula that was developed to determine the area to be patrolled each danger day, given the total amount of money allocated to highdanger days during the ten fire seasons, is

$$
\begin{gathered}
\mathrm{A}=(\mathrm{SM} / \mathrm{C})[15 / \mathrm{D}(15)+12 / \mathrm{D}(12) \\
+9 / \mathrm{D}(9)+6 / \mathrm{D}(6)]
\end{gathered}
$$

Where-

$\mathrm{A}$ is the area patrolled each high-danger day (sq. mi.)

$\mathrm{S}$ is the speed of the aircraft in miles per hour

( $\mathrm{S}$ was given the value of 90 miles per hour)

$\mathrm{M}$ is the amount of money available to spend on high-danger days (this was the main design variable)

$\mathrm{D}(\mathrm{J})$ is the number of days of high danger and $\mathrm{J}$ miles visibility

$\mathrm{C}$ is the cost per hour of an aircraft ( $\mathrm{C}$ was given the value of 40 dollars per hour).

Areas patrolled each day were calculated.

For each of the five budget levels examined, many different allocations of money to each danger class day were made. Using the previous formula, the resulting number of square miles patrolled each danger class day was found. Rules for each danger class day were devised to utilize this area. These rules were design variables and were changed many times. Air patrols were allotted by sectors. The available areas could be used up by patrolling one sector several times or by patrolling some amount in all three sectors. Any allocations of patrols to the sectors was allowed provided the total area covered equalled the allotted area. Fractions of flights over sectors were allowed.

Another design variable for the allaircraft section of the model was the time of each patrol. If a complete patrol were scheduled for hour seven over sector two, it was assumed that every point in sector two was covered at hour seven and that every fire that started after the previous patrol in sector two would be detected at hour seven, provided that it was not detected by the public first. Patrols were no closer than one hour apart over the same sector and a partial patrol over a sector was carried out during the last patrol of the day. (The probability of detecting a fire during a partial patrol is described later).

An example showing one of the many all-aircraft alternatives available for the 54,000 dollar ten-year budget is given below.

The same budget levels as used for the all-lookout section were used in the all-aircraft and combined sections.

A mechanism similar to the fire detection generator was built into the model to handle the partial flights. If the value of a random number were less than the proportion of the total area covered by the flights, the air patrol detected the fire. It was assumed that a complete air

EXAMPLE OF AN ALL-AIRCRAFT DETECTION ALTERNATIVE

\begin{tabular}{|c|c|c|}
\hline Danger class & $\begin{array}{l}\text { Allocation } \\
\text { of budget }\end{array}$ & $\begin{array}{l}\text { Daily area to } \\
\text { be patrolled }\end{array}$ \\
\hline & dollars & $s q . m i$ \\
\hline High............ & 34,000 & 4,685 \\
\hline Moderate......... & 20,000 & 579 \\
\hline Low........ & 00 & 0 \\
\hline
\end{tabular}

(Amount of money in the budget $=\$ 54,000$ ) 


\section{COST EFFECTIVENESS CURVES OF THE ALL-LOOKOUT AND ALL-AIRCRAFT DETECTION SYSTEMS}

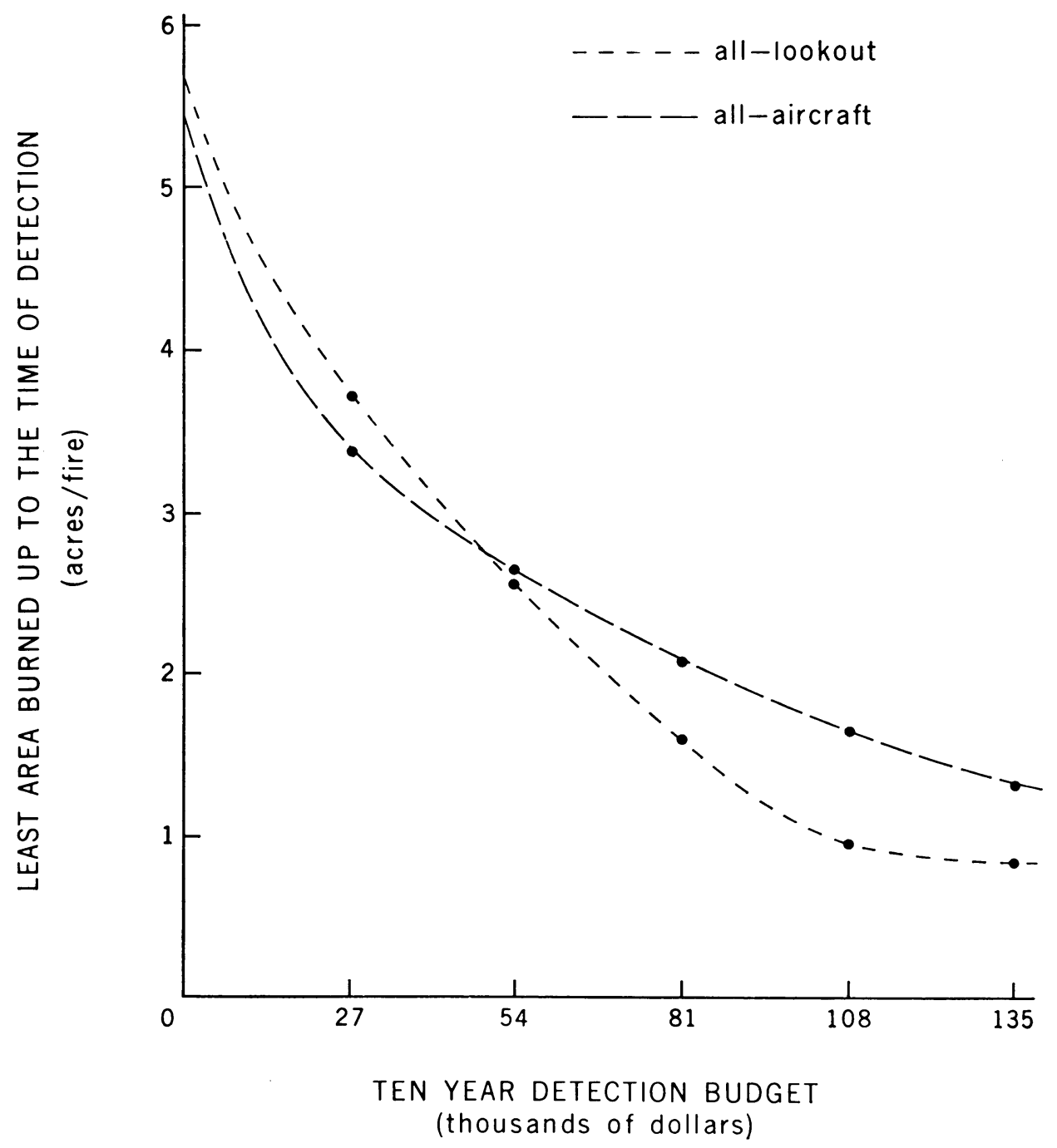

Fig. 5. Cost-effectiveness curves of the all-lookout and all-aircraft detection systems. 
PATROL PLAN

\begin{tabular}{c|c|c|c}
\hline Hour of flight & $\begin{array}{c}\text { Number } \\
\text { of flights }\end{array}$ & Sector & $\begin{array}{r}\text { Area } \\
\text { patrolled }\end{array}$ \\
\hline High-danger days: & & & sq. mi. \\
$3,5,7,9 \ldots \ldots \ldots \ldots \ldots \ldots$ & 4.00 & 1 & 2,380 \\
$4,7,9 \ldots \ldots \ldots \ldots \ldots \ldots$ & 2.50 & 2 & 1,500 \\
$7 \ldots \ldots \ldots \ldots \ldots \ldots \ldots$ & 1.00 & 3 & 805 \\
Total area....... & & & 4,685 \\
\hline Moderate-danger days: & & & \\
$7 . \ldots \ldots \ldots \ldots \ldots \ldots$ & $0.97^{*}$ & 1 & 579 \\
Total area........ & & & 579 \\
\hline
\end{tabular}

* This fraction of a flight was obtained by dividing the area available to patrol (579) by the total area of Sector One (595).

patrol over a sector would detect all detectable fires. If a fire started after the last patrol, it would spread until the tenth hour at a rate governed by the current day's danger index and would continue increasing in area the next day at the rate governed by the second day's danger index. It would continue to burn until it was detected by an air patrol or by the public. The situation when no patrols were carried out over a sector was similar to the all-lookout situation when fires occurred outside the visual range of the lookouts. In both cases the public detected the fires.

The model cumulated the areas burned up to the time of detection as well as the number of fires detected. The same ten years of environment data were used for each new detection alternative. The effectiveness of the best detection alternative found at each budget level is given below.

\begin{tabular}{|c|c|}
\hline Budget level & Effectiveness \\
\hline dollars & acres \\
\hline $00 \ldots \ldots \ldots \ldots$ & 5.57 \\
\hline $27,000 \ldots \ldots \ldots \ldots \ldots$ & 3.41 \\
\hline $54,000 \ldots \ldots \ldots \ldots \ldots$ & 2.57 \\
\hline $81,000 \ldots \ldots \ldots \ldots \ldots$ & 2.10 \\
\hline $108,000 \ldots \ldots \ldots \ldots \ldots \ldots \ldots$ & 1.65 \\
\hline $135,000 \ldots \ldots \ldots \ldots \ldots \ldots \ldots$ & 1.37 \\
\hline
\end{tabular}

Figure 5 shows the all-aircraft and the all-lookout cost-effectiveness curves plotted together.

\section{THE COMBINED LOOKOUT-AIRCRAFT SECTION OF THE MODEL}

A combined lookout-aircraft system can be viewed merely as an alllookout system covering one part of the protection unit and an all-aircraft system covering the remaining part. The proportion of the protection unit that each system covers changes with the visibility and patrolling assignments.

The combined section of the model required the same probabilities of not detecting fires in each sector for each lookout combination that were used in the all-lookout section of the model. Using these, the number of fires not detected by lookouts in each sector, each day, was found in the same manner as used previously. The remaining fires were detected either by the air patrols or by the public, exactly the same as in the all-aircraft section of the model. The general flow diagram of the model is illustrated in figure 1.

The design variables for the combined detection system are given below.

The budget. Five budgets were examined.

The proportion of the budget spent on lookouts and air patrols. For all five budgets, the maximum number of budget allocations was ten since no fractions of lookouts could be operated (see table on page 361, bottom). For each of the ten budget allocations, many different alternatives were examined.

The location of lookouts that were to be operated. This design variable specified which lookouts were to be operated. The design variable described in the point above set the number of lookouts to be operated. 


\section{COST EFFECTIVENESS CURVES OF THE ALL-LOOKOUT, ALL-AIRCRAFT AND COMBINED DETECTION SYSTEMS}

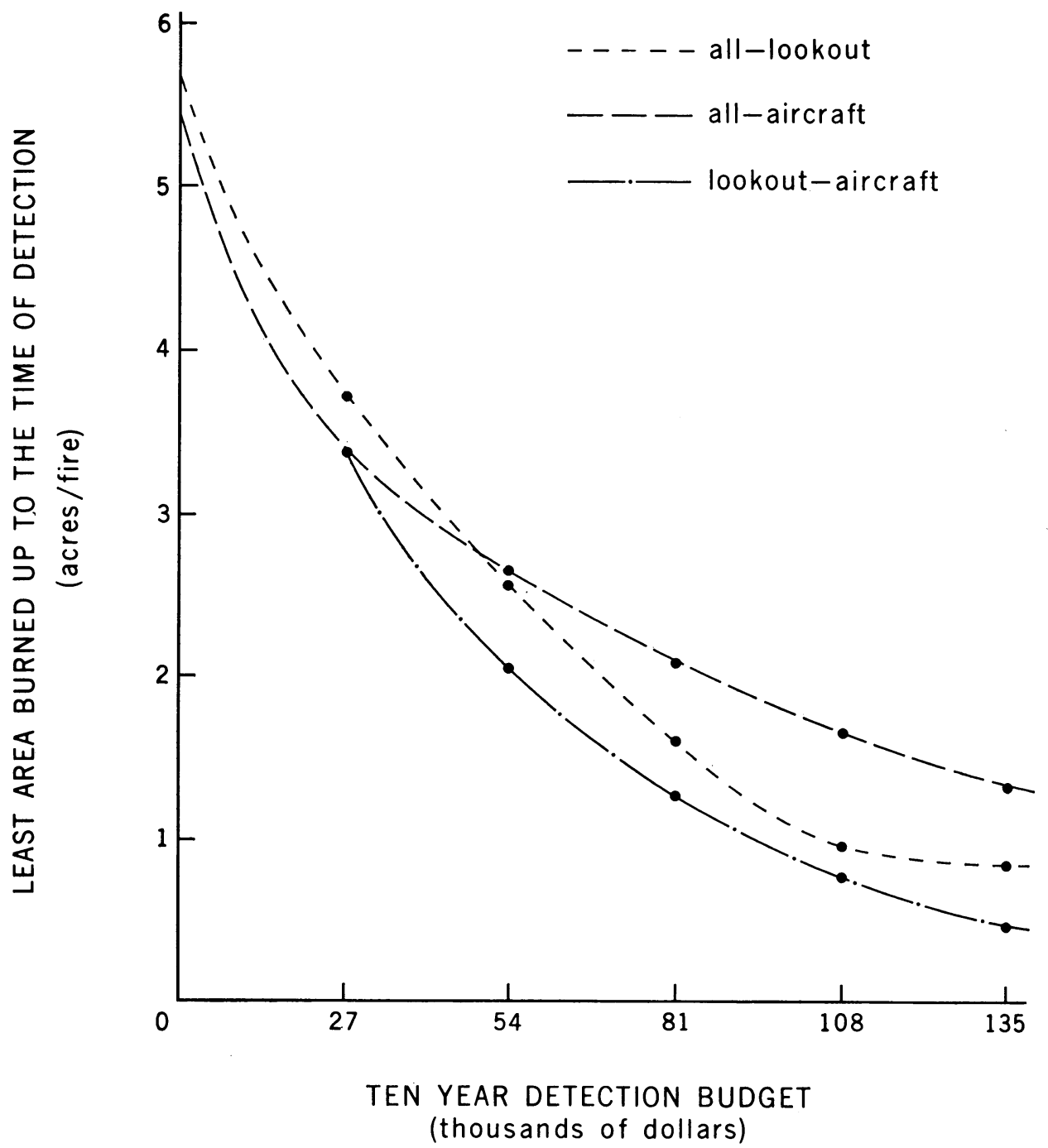

Fig. 6. Cost-effectiveness curves of the all-lookout, all-aircraft, and combined detection systems. 
The number of patrols over the areas not protected by lookouts in each sector on each danger class day: the area not protected by lookouts in each sector varies from day to day because of fluctuating visibilities. Therefore, an allocation based on a specified number of square miles to be patrolled each danger class day would result in an inconsistent detection policy. This problem was overcome by allocating the money by danger-class days and by the number of complete patrols over the remaining areas not covered by the lookouts in each sector. Therefore, regardless of the visibility, the area not covered by lookouts in each sector was patrolled an equal number of times on each danger-class day. This method of allocation insured that the amount spent over the ten fire seasons equalled the budget constraint. The formula that was used to calculate the number of flights over the remaining area of sector 1 each high-danger day is given below. Partial flights over the remaining area were allowed.

$$
\begin{gathered}
\mathrm{F}=(\mathrm{MS} / \mathrm{C})\{15 /[\mathrm{A}(15) \mathrm{D}(15)] \\
+12 /[\mathrm{A}(12) \mathrm{D}(12)]+9 /[\mathrm{A}(9) \mathrm{D}(9)] \\
+6 /[\mathrm{A}(6) \mathrm{D}(6)]\}
\end{gathered}
$$

Where-

F represents the number of air patrols over sector 1 on a high-danger day (the value of this design variable depends upon the amount of money allocated to sector 1 for high-danger days)

$\mathrm{M}$ is the amount of money spent in sector 1 on the high-danger days (this is the main design variable)

$\mathrm{S}$ is the speed of the aircraft in miles per hour

$\mathrm{C}$ is the cost of the aircraft in miles per hour

$A(J)$ is the area not covered by lookouts in sector 1 when the visibility is
$J$ miles (this depends on the number of lookous being operated)

$\mathrm{D}(\mathrm{J})$ is the number of days occurring in the high-danger class with $\mathrm{J}$ miles visibility.

The time of each air patrol. The rules governing the use of this last design variable were exactly the same as those of the all-aircraft section. A feasible allocation of 108,000 dollars is shown here:

\section{A FEASIBLE ALLOCATION OF 108,000 DOLLARS TO A COMBINED SYSTEM}

(Note: The two lookouts operated were Lookouts 1 and 3. Amount spent on lookouts and aircraft was $\$ 54,000$ each.) AIRCRAFT ALLOCATION

\begin{tabular}{c|c|c|c}
\hline \hline Hour of flights & $\begin{array}{c}\text { Number } \\
\text { of flights }\end{array}$ & Sector & $\begin{array}{r}\text { Amount } \\
\text { allocated }\end{array}$ \\
\cline { 1 - 3 } High-danger days: & & & dollars \\
$3,5,6,7,9 \ldots \ldots \ldots$ & 4.67 & 1 & 6,000 \\
$3,5,7,9 \ldots \ldots \ldots \ldots$ & 4.00 & 2 & 9,000 \\
$5,8,9 \ldots \ldots \ldots \ldots$ & 2.10 & 3 & 11,000 \\
\hline Moderate-danger days: & & & \\
$5,8,9 \ldots \ldots \ldots \ldots$ & 2.04 & 1 & 18,000 \\
$7 \ldots \ldots \ldots \ldots \ldots$ & 0.81 & 2 & 10,000 \\
& & &
\end{tabular}

After many computer trials of feasible alternatives, for each of the ten budgets, the alternatives that resulted in the lowest area burned per fire up to the time of detection were selected. The results were as follows:

\begin{tabular}{c|c|c}
\hline $\begin{array}{c}\text { Amount spent } \\
\text { on lookouts }\end{array}$ & $\begin{array}{c}\text { Amount spent } \\
\text { on aircraft }\end{array}$ & $\begin{array}{c}\text { Best effectiveness } \\
\text { achieved }\end{array}$ \\
\hline $27,000 \ldots \ldots \ldots \ldots$ & 27,000 & 2.06 \\
$27,000 \ldots \ldots \ldots \ldots$ & 54,000 & 1.26 \\
$27,000 \ldots \ldots \ldots \ldots$ & 81,000 & 1.15 \\
$27,000 \ldots \ldots \ldots \ldots$ & 108,000 & 1.01 \\
$54,000 \ldots \ldots \ldots \ldots$ & 27,000 & 1.26 \\
$54,000 \ldots \ldots \ldots \ldots$ & 54,000 & 0.82 \\
$54,000 \ldots \ldots \ldots \ldots$ & 81,000 & 0.69 \\
$81,000 \ldots \ldots \ldots \ldots$ & 27,000 & 0.78 \\
$81,000 \ldots \ldots \ldots \ldots$ & 54,000 & 0.59 \\
$108,000 \ldots \ldots \ldots \ldots$ & 27,000 & 0.47 \\
\hline
\end{tabular}

Figure 6 illustrates the graph of the cost-effectiveness data for the three alternatives. 


\section{DISCRETE SOLUTION BASED ON THE ORIGINAL DATA \\ FROM THE MODEL}

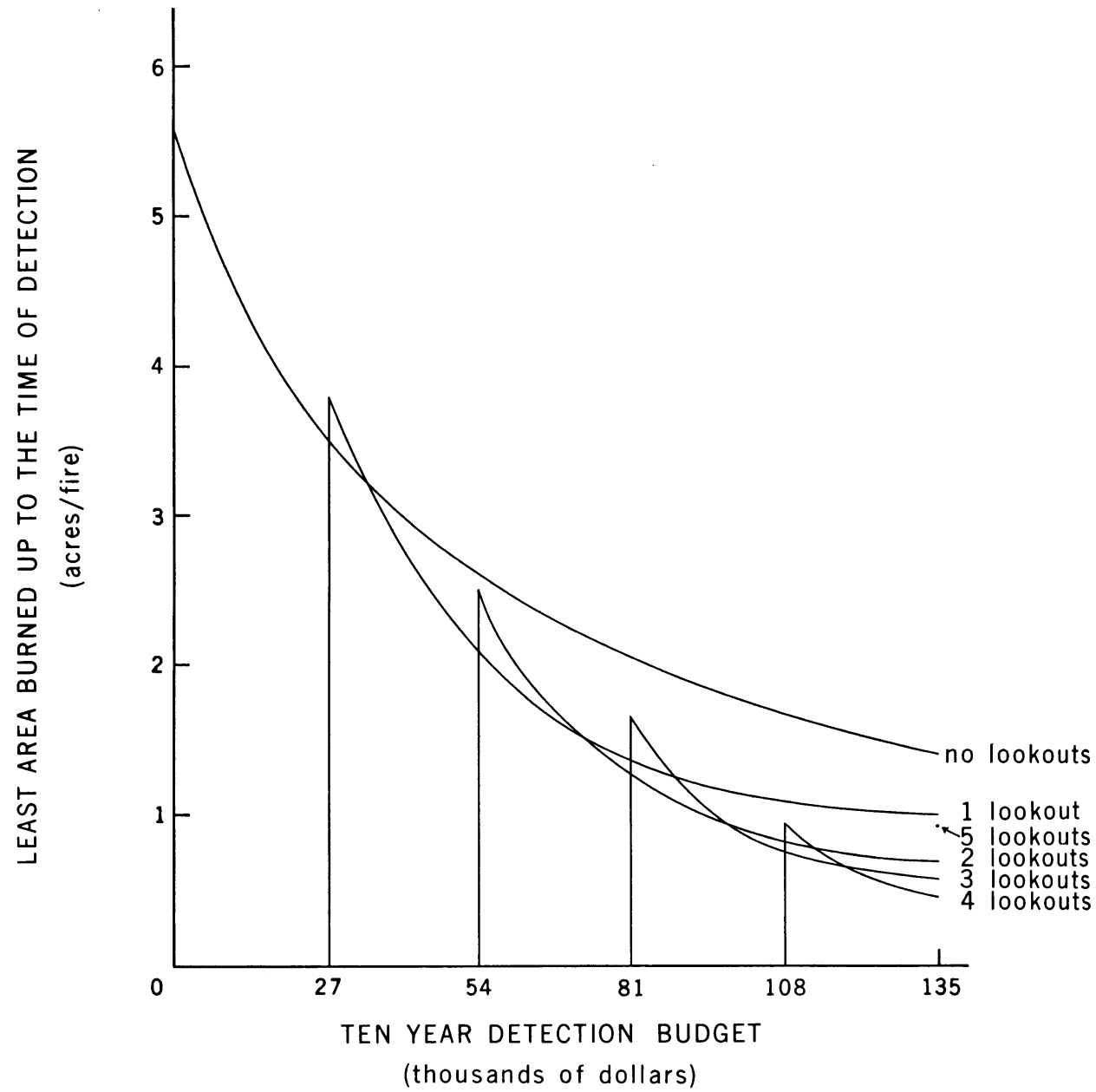

Fig. 7. Discrete solution based on the original data from the model. 


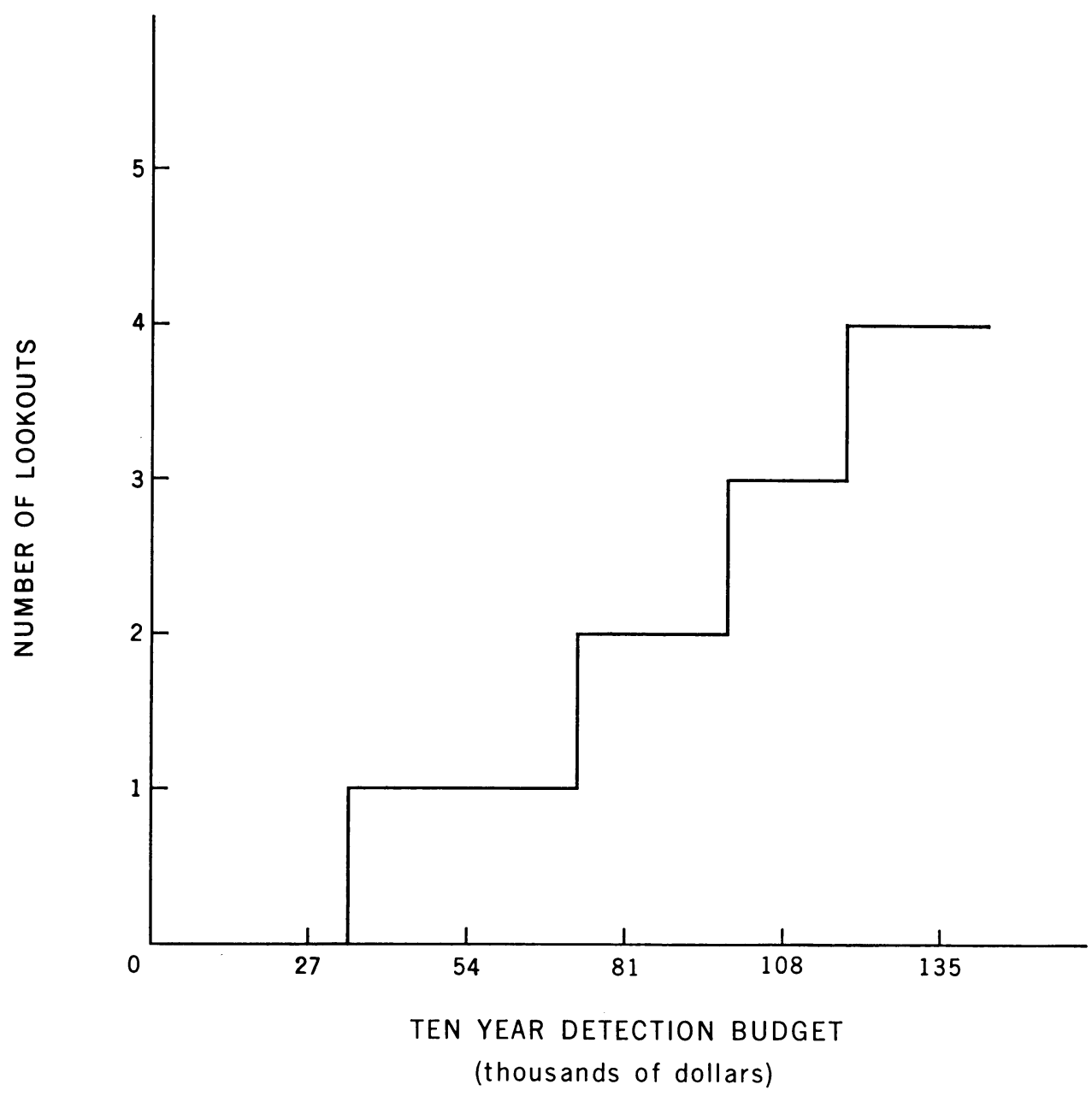

Fig. 8. Number of lookouts to operate given the ten-year budget.

\section{THE EFFICIENT SOLUTION}

If fractions of lookouts could be operated, econometric methods could be used to fit and examine the estimated response surface. Iso-effectiveness curves could be drawn once the form of the surface was known. The point of tangency of an iso-cost and iso-effective- ness curve would be the combination at which substitution of aircraft hours for lookouts could no longer increase effectiveness. The line joining many such points would represent the path of efficient solutions or the expansion path. The efficient combination of lookouts 


\section{AMOUNT TO SPEND ON AIRCRAFT GIVEN THE TEN-YEAR BUDGET}

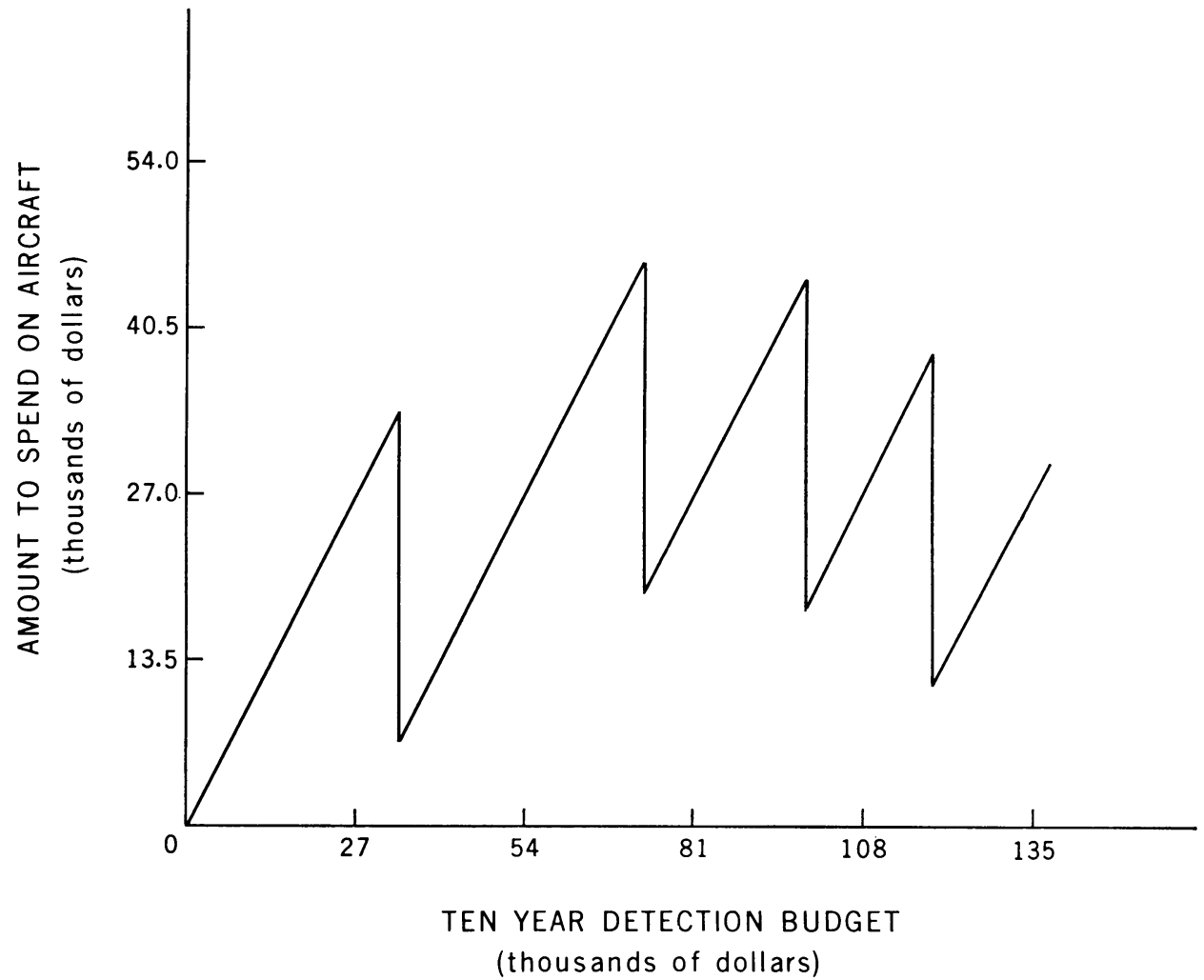

Fig. 9. Amount to spend on aircraft given the ten-year budget.

and aircraft could be found for any budget level at the intersection of the expansion path and the appropriate isocost curve. However fractions of lookouts cannot be operated and thus the continuous solution produced by these methods would be invalid. The discrete and not the continuous solution was required.

Figure 7 presents the discrete solution based on the data produced by the model for all budgets. The best combination of lookouts and aircraft for a given budget can be found by projecting a vertical line from the horizontal axis at the appropriate budget level. The number of lookouts corresponding to the lowest curve that intersects this vertical line is the appropriate number of lookouts to operate. For example, if 87,000 dollars were available over a ten-year period, two lookouts should be operated and the remaining 33,000 dollars $(87,000-2 \times 27,000)$ should be spent on air patrols. The data used to obtain the curves in figure 7 came from the tables on pages 353 , col. 2, 359, col. 2 , and 361 , bottom.

Figure 8 indicates the amount that should be spent on lookouts given the ten-year budget. Figure 9 indicates the amount that should be spent on air patrols given the ten-year budget. 


\section{DISCUSSION}

The results obtained from the analysis of the hypothetical data must not be generalized. Each protection unit will have its own unique solution. It also should be realized that the model did not consider many other factors that could influence a decision regarding the best detection system. Some of these factors are:

The value of the forest being protected. A great deal of work is currently being carried out in the field of forest evaluation and fire-damage appraisal. In the near future research along these lines may progress to a state that will enable the use of a criterion that considers these factors. The versatility of the lookouts and aircraft. Lookouts have long been used as weather stations and communications relays. A decision to abandon a lookout should take these factors into consideration. Aircraft, on the other hand, can be used for ferrying men and equipment and obtaining intelligence information from going fires when they are not required for detection patrols.

Reliability of the system. Occasionally at critical periods bad flying weather or mechanical failures can ground patrol aircraft. With lookouts, a disinterested group of lookoutmen can significantly decrease the effectiveness of a lookout system.

Decision makers must weigh these and other factors along with the results obtained from this technique before the final allocation is made.

The major weakness of this technique is its reliance on a general fire model. The fire model used was the best available for this purpose. However, its use could be improved even now by determining the danger index at many different times throughout the day. This would avoid the assumption that fires start and burn only during ten hours each day.

In applying this technique, the time consuming job would be the preparation of actual environment data in a form suitable for the model and the determining of the areas not covered by lookouts in each occurrence sector from area-seen maps. The computer time required for the solution for the hypothetical forest, once the programs were developed, was less than two hours on the University of California's direct couple IBM 7040-7094 system. The execution of a combined detection alternative using the environment data for ten fire seasons required 50 seconds. Altogether, approximately 150 different detection alternatives were examined.

Many parameters such as the cost and speed of the aircraft were treated as variables in the computer programs. Consequently different values of these parameters can be used without changes in the programs. To suit local conditions, assumptions and constraints used in the program can be altered rather easily.

\section{Acknowledgments}

The research for this paper was partially financed by the Fire Research Laboratory of the Intermountain Forest and Range Experiment Station of the United States Forest Service through the Forest Service's arrangements with the University of California. This assistance is gratefully acknowledged.
The authors gratefully acknowledge the grant of computer time given to them by the Computer Center of the University of California.

Appreciation is extended to the Canadian Department of Forestry for the educational leave and financial support granted to Peter Kourtz.

Professor W. M. McKillop and Pro- 
fessor W. S. Jewell served on the committee guiding the thesis out of which this paper grew.

Note: The computer programs described in this publication may be obtained at the School of Forestry and Conservation, Berkeley.

\section{LITERATURE CITED}

BARrows, J. S.

1951. Forest fires in the Northern Rocky Mountains. Station Paper 28, Northern Rocky Mountain Forest and Range Experiment Station, Forest Service, U.S.D.A.

HARRis, H. K. and G. R. FAHNESTOCK

1945. Aerial observation versus lookout. Fire Control Notes, Forest Service, U.S.D.A. 15(2). Hitch, J. C. and R. N. McKeAN

1960. The economics of defense in the nuclear age. Cambridge, Mass.: Harvard University Press.

PARKs, G. M.

1964. Development and application of a model for suppression of forest fires. Management Science $10(4)$.

To simplify the information, it is sometimes necessary to use trade names of products or equipment. No endorsement of named products is intended nor is criticism implied of similar products not mentioned. 
The journal HILGARDIA is published at irregular intervals, in volumes of about 650 to 700 pages. The number of issues per volume varies.

Single copies of any issue may be obtained free, as long as the supply lasts; please request by volume and issue number from:

$$
\begin{aligned}
& \text { Agricultural Publications } \\
& \text { University Hall } \\
& \text { University of California } \\
& \text { Berkeley, California } \mathbf{9 4 7 2 0}
\end{aligned}
$$

The limit to nonresidents of California is 10 separate titles. The limit to California residents is 20 separate titles.

The journal will be sent regularly to libraries, schools, or institutions in one of the following ways:

1. In exchange for similar published material on research.

2. As a gift to qualified repository libraries only.

3. On a subscription basis- $\$ 7.50$ a year paid in advance. All subscriptions will be started with the first number issued during a calendar year. Subscribers starting during any given year will be sent back numbers to the first of that year and will be billed for the ensuing year the following January. Make checks or money orders payable to The Regents of The University of California; send payment with order to Agricultural Publications at above address. 